\title{
A Systematic Process for Recruiting Physician-Patient Dyads in Practice-based Research Networks (PBRNs)
}

\author{
Hubert Robitaille, PhD, France Légaré, MD, PhD, and Ghislaine Tre, PhD
}

Background: Recruiting physicians and patients for primary care research is difficult, and low participation can greatly affect the validity of research. While practice-based research networks (PBRNs) offer advantages of scale for recruitment, the barriers are perennial. We designed a systematic process for recruiting physician-patient dyads in PBRNs and tested it in EXACKTE2, a large, cross-sectional, dyadic study.

Methods: Based on known barriers, we designed a systematic process for recruiting dyads of family physicians and their patients and implemented it in 2 primary care practice-based research networks in Canada: one in Ontario (11 practices) and one in Quebec (6 practices). Dyads (one physician with one patient) were recruited simultaneously to explore their mutual influence during consultations. A key element of the process was a research assistant assigned to each practice. This person closely accompanied the recruitment process, liaising with staff and taking charge of interviews, questionnaires, and follow-up.

Results: In total, 276 physicians and patients were recruited in 17 primary care practices in 2 primary care networks in Ontario and Quebec, representing a participation rate of more than $72 \%$ of eligible physicians and more than $64 \%$ of eligible patients.

Conclusion: We established a systematic process to conduct successful dyadic recruitment of physicians and patients in PBRNs.(J Am Board Fam Med 2014;27:740-749.)

Keywords: Patient Recruitment, Practice-based Research, Primary Health Care

One of the most important challenges in clinical practice-based research is the recruitment and retention of enough study participants. ${ }^{1-3}$ Low participation rates reduce statistical power, compromise the validity of results, and can lead to an extended project timeline. ${ }^{3,4}$ In the worst case scenario, unsuccessful recruitment may lead to trial suspension, ${ }^{5}$ which can discourage research-

This article was externally peer reviewed.

Submitted 18 January 2014; revised 1 May 2014; accepted 9 May 2014.

From the CHU de Québec Research Centre-Hôpital St-François d'Assise/University Laval, Québec City, Québec, Canada (HR, FL); and the Department of Family Medicine and Emergency Medicine, University Laval, Québec City, Québec, Canada (FL, GT).

Funding: This study was funded by the Canadian Institutes of Health Research (CIHR 2008-2011, grant no. 185649-KTE). FL is Tier 2 Canada Research Chair in Implementation of Shared Decision Making in Primary Care.

Conflict of interest: none declared.

Corresponding author: France Légaré, MD, PhD, CHU de Québec Research Centre-Hôpital St-François d'Assise, 10, Rue Espinay, Quebec City, QC, Canada G1L 3L5 (E-mail: France.legare@mfa.ulaval.ca). ers and recruits from getting involved in further trials. One third of trials in the United Kingdom are forced to seek additional funding because of recruitment delays. ${ }^{6}$ Researchers are often too optimistic when they predict the number of eligible clinicians, and the rate of participation is generally lower than expected. ${ }^{7}$ A poor choice of context and timing may also affect the success of the recruitment. ${ }^{8-10}$

Barriers to clinician participation have been identified by numerous studies. ${ }^{9-11}$ One barrier for clinicians and their staff is time constraints. ${ }^{12-14}$ Another is lack of staff and adequate training for those performing the clinical research projects. ${ }^{15-17}$ Some clinicians fear that research activities will disturb their practice ${ }^{18}$ by disrupting staff or harming relationships with their patients. ${ }^{19,20}$ Clinicians express concerns about the burden of research activities on their patients. ${ }^{21,22}$

In the past 20 years, interest in a dyadic approach to practice-based health care research has grown. ${ }^{23-27}$ In the dyadic approach, both patient 
and physician are considered together to account for the impact of their interaction, reciprocity, and interdependence. ${ }^{27}$ Research involves the enrollment of patients at the same time as their physicians while maintaining confidentiality, which adds an extra dimension to the recruitment challenges. Recruiting patients is notoriously difficult; they often decline to participate in trials, citing as reasons a reluctance to comply with research protocols, the need for follow-up appointments, concerns about questionnaires, and lack of interest in research. ${ }^{28-30}$ Moreover, patients may misunderstand the objectives of the study or may even mistrust the investigators. $^{31,32}$

Another problem with patient recruitment is that it is often clinicians who recruit them, using their judgment to apply institutional review board eligibility criteria. This can lead to selection bias and variation from one clinician to another regarding patient eligibility, lack of time, lack of motivation, and lack of representativeness. ${ }^{28}$ In addition, clinicians are less likely to recruit patients with problems and more likely to refer only "good" study candidates. ${ }^{9}$

Practice-based research networks (PBRNs) are groups of primary care clinicians and practices working together to answer primary health care research questions and translate their findings into practice (http://pbrn.ahrq.gov/). With $90 \%$ of all patient contacts occurring in primary care, ${ }^{33}$ PBRNs offer access to a large number of patients with a wide variety of clinical conditions. ${ }^{34}$ Physician and patient recruitment in PBRNs can be improved using "champions," who make initial contacts and establish a relationship with clinic staff. ${ }^{10}$ However, despite a large pool of potential recruits and apparent ease of access, clinician participation rates vary greatly and may threaten the representativeness of findings. ${ }^{10,35} \mathrm{New}$ methods need to be developed to improve recruitment rates and reduce the time required to achieve study objectives.

This article describes an original and systematic recruitment process that was designed to overcome the main barriers to enrolling family physicianpatient dyads in PBRNs. Using this recruitment strategy, we performed a cross-sectional dyadic study, EXACKTE2,25,26 with the purpose of collecting data from pairs of family physicians and their patients.

\section{Description of the EXACKTE2 Project}

This cross-sectional study enrolled 276 family physicians and their 276 patients at sites in London, Ontario, and Québec City, Québec, Canada. Based on a dyadic approach to knowledge transfer, the study assessed the validity and reliability of dyadic questionnaires and tested the degree to which patients and physicians influenced each other. Data were collected from family physicians and their patients (one each) for any clinical decision. Consultations between patients and physicians were audiotaped and transcribed. Following the consultation, patients and physicians completed similar questionnaires. Patients were called 2 weeks later and asked to complete questionnaires on decisional regret and quality of life.

\section{Methods}

\section{Strategy}

We designed our systematic recruitment strategy based on an environmental scan of the literature on recruitment problems, ${ }^{29,35}$ as well as based on recommendations and suggestions made by clinicians and patients during our earlier research projects. ${ }^{36-38} \mathrm{We}$ deduced that good communication and relationships between clinicians and researchers are key elements for overcoming recruitment barriers and that our "champion" would be a specially trained and highly qualified research assistant (RA) assigned to each practice group who would be closely involved throughout the recruitment process. We hypothesized that this would reduce time and staff resources normally required of a recruited practice group and would improve confidence in the study among patients and clinicians. As a patient recruiter, the RA would also reduce problems associated with patient recruitment by clinicians, including selection bias. The RA would recruit patients and physicians at the same time while maintaining confidentiality, a requirement for dyadic research. Finally, the RA would carefully time interventions to address the problems of time constraints frequently identified as barriers by physicians and patients.

For our EXACKTE2 study, recruitment targeted 2 academic PBRNs affiliated with the University of Western Ontario, in the area of London, Ontario, Canada, and with the Universite Laval, in the area of Québec City in Québec, Canada. Our objective was to recruit 300 unique patient-physician dyads ${ }^{25}: 150$ in the University of Western Ontario PBRN and 150 in the Université Laval PBRN. ${ }^{25}$ 
Figure 1. Recruitment process for clinics and patientphysician dyads. FPTU, Family Practice Teaching Unit.

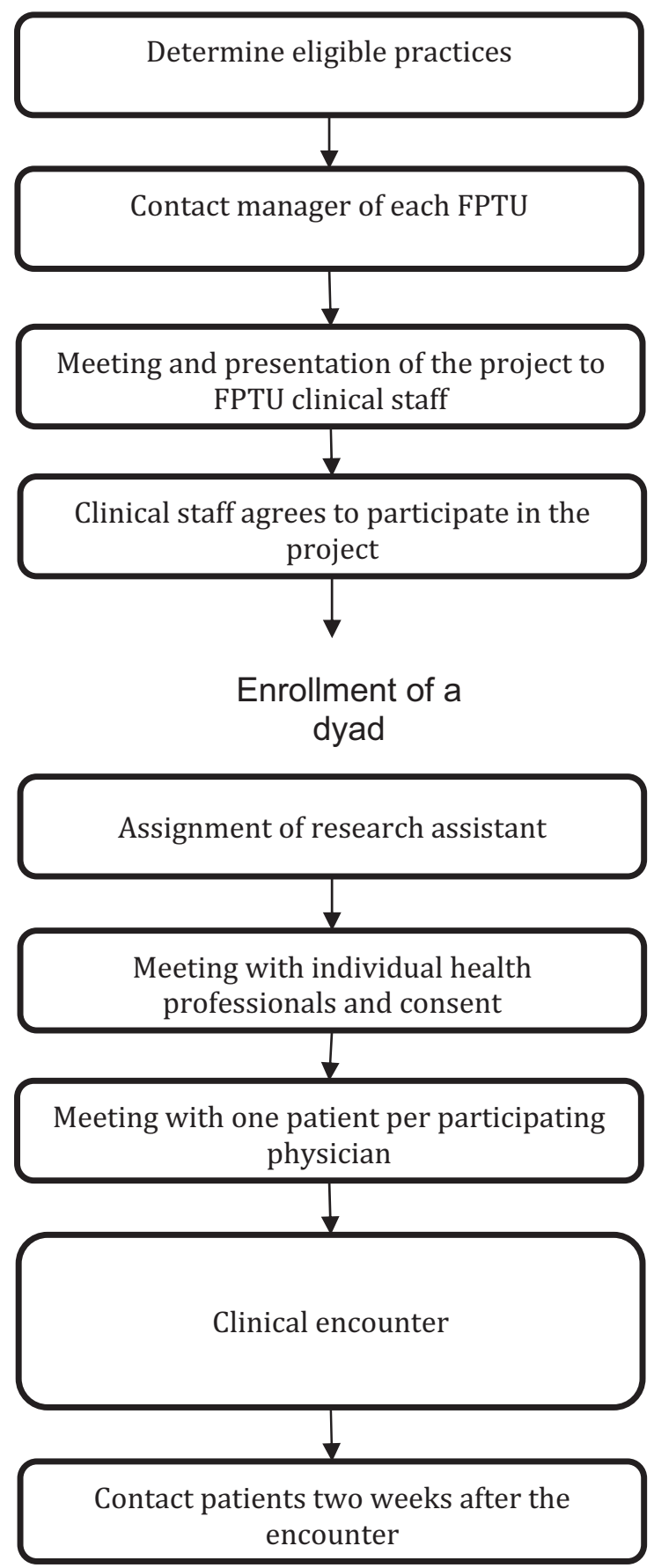

\section{Recruitment Process}

The recruitment process consisted of 9 steps (Figure 1).

\section{Step 1: Determine Eligible Practices}

The first step was determining the sample size required to obtain representative results and the type of practice needed to recruit targeted patient and health professional populations (eg, rural vs urban, physicians vs residents).

\section{Step 2: Contact the Manager of Each Family Practice Teaching Unit (FPTU)}

The primary investigator (PI) or the research coordinator contacts the manager or representatives of the Family Practice Teaching Unit (FPTU) to determine whether they are interested in having the project presented to the physicians and other staff. A brief description of the study is then sent to the managers, who are asked to provide a date for a possible presentation.

\section{Step 3: Meeting and Presentation of the Project to the FPTU's Clinical Staff}

Once the manager of each FPTU provides consent to the presentation of the study, the PI makes a 30-minute PowerPoint presentation to the staff at the FPTU. The presentation takes place during a lunch hour or an administrative meeting, during which the PI introduces the RAs to the clinical staff.

\section{Step 4: Clinical Staff Agrees to Participate in the Project}

The clinical staff is asked to reflect on their participation in the project and to collectively consent to their FPTU taking part in the project. This consent is communicated by the FPTU manager in a letter to the research group.

\section{Step 5: Assignment of RA}

RAs are assigned to each site and begin making contact with clinical and administrative staff. To keep up momentum, the recruitment timetable is managed such that an RA is continuously present on each site throughout the recruitment phase. From this point on, administrative staff work with the RA on scheduling clinical staff to maximize recruitment efficiency.

\section{Step 6: Meeting With Individual Health Professionals and Consent}

Using the daily clinical schedule, the RAs plan to meet each potentially eligible health professional to invite them individually to participate in the study. The RA meets them just before the beginning of their clinical encounters, briefly presents the study ( 2 to 3 minutes), and gives them an information sheet and the informed consent form. Then, if the 
health professional agrees to participate, they agree on a schedule for patient recruitment and on when to begin.

\section{Step 7: Meeting With One Patient per Participating Physician}

At the agreed time, the RA asks the administrative staff to provide a list of patients who have appointments with the participating physicians. The physician then identifies those who are ineligible for that particular study, for example, because of cognitive impairment. The RA stands in the FPTU waiting room and verifies whether the patients arriving are on the list of eligible patients. Because the RA meets and recruits the patient beforehand, any delay in the physician's appointment schedule is avoided. The RA, trained to describe the benefits and impacts of the project in nonscientific language, then briefly presents the project to the patients by showing them the information sheet and the consent form, asks whether they are interested in participating, and informs them that their physician has agreed to participate, too.

\section{Step 8: Clinical Encounter}

Once the patient agrees to participate in the project and the physician calls in the patient for the appointment, the RA accompanies the patient into the consulting room and places the voice recorder on the physician's desk. Then the RA leaves the room, waits until the end of the encounter to retrieve the voice recorder, and requests that the physician and the patient complete their respective questionnaires. The physician usually completes the questionnaire in the consulting room while the RA accompanies the patient into another room (eg, a PBRN research room) to compete his or her own questionnaire. The RA can answer any questions about the questionnaire and notes the patient's phone number and a time (day and time of day) convenient for contact for the 2-week follow-up. When the patient and the physician have completed their questionnaires, the RA collects them and verifies all the data.

\section{Step 9: Contact Patients 2 Weeks After the Encounter}

The RA contacts the patients at the agreed time to conduct a phone questionnaire about how they followed up on their encounter and outcomes related to the decision that was made.

\section{Recruitment Follow-up}

Each RA keeps a daily tracking file in which they record all the patients approached, estimated age of patients refusing to participate, reason for consultation of patients refusing to participate (if available), and any information about recruitment. The RA follows up with the FPTU administrative staff to find out about newly eligible or ineligible physicians. At the end of each week, tracking files are verified and all RAs hold a team meeting with the research coordinator and the PI.

\section{Recruitment Updates for Physicians}

The RA regularly files a recruitment update in physicians' mailboxes to keep them abreast of any news or recruitment progress in their clinic and in the whole project. Clinic managers also are informed of project-related poster presentations and publications.

\section{Results}

\section{Research Assistants}

We enrolled 6 RAs to cover the 6 FPTUs in Quebec and 2 research assistants in Ontario (in Ontario, the schedules of eligible physicians were more flexible, giving the RAs the opportunity to cover more than 1 site). Recruitment training included role play with a validated script simulating a situation of recruitment of health professionals and patients. In Quebec, the trained RAs were 2 experienced project managers who had conducted a similar study and 4 students who had been involved in the study (a student studying for an MSc in Community Health, a student studying for a $\mathrm{PhD}$ in Human Resources, a second-year medical student, and a student studying for a $\mathrm{PhD}$ in Epidemiology). In Ontario, trained RAs were 2 experienced project managers who were trained by the senior RA and PI in Quebec.

\section{Participating Physicians}

The EXACKTE2 study lasted 9 months in the Western Ontario network and 11 months in the Université Laval network. While recruitment in the Ontario sites was considered a single phase, recruitment in the 6 Quebec sites lasted 9 months (sites 1, 2, and 3), 7 months (site 4), 5 months (site 5), and 3 months (site 6) (Figure 2). A total of 405 physicians were available on the lists provided by each FPTU. Of these, 23 (5.7\%) were ineligible. 
Figure 2. Recruitment periods for participating family practices

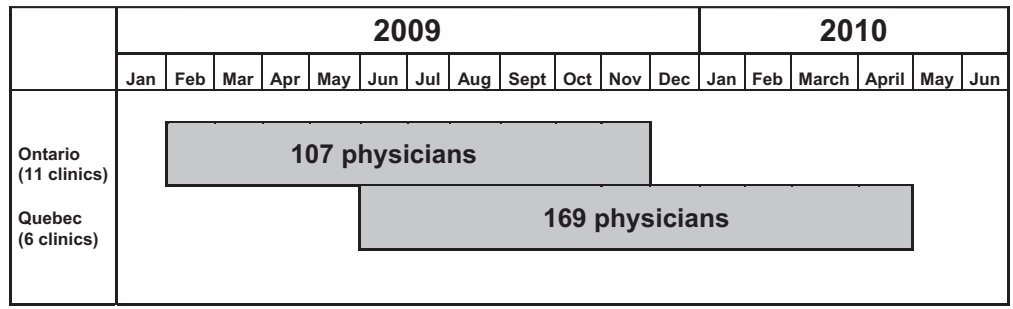

Of the 382 eligible physicians (94.3\%), 55 (14.4\%) were not reachable and $51(13.4 \%)$ refused to participate. That left 276 participating physicians (Table 1) who signed consent forms. Figure 3 is a flow diagram showing the physician and patient enrollment process.

As shown in Table 2, the mean age of participating physicians was 35.4 years. Ontario physicians recruited were slightly older (average age of 37.6 compared with 34.0 in Quebec). More than $71 \%$ of the Ontarian physicians recruited were residents, compared with $49 \%$ in Quebec.

\section{Participating Patients}

In the EXACKTE2 study, numbers of total eligible patients were not available because before each consultation schedule, each physician selected a list of potential patients, excluding those with signs of mental disorders and those unable to read and complete the questionnaire. A total of 430 patients were asked to participate. Of these, only 9 (2\%) were ineligible to participate; 142 (33\%) refused, and 3 $(0.7 \%)$ withdrew from the study (Table 3$)$. Reasons for refusal were similar in Ontario and Quebec and were mainly time constraints (51\%), lack of interest (20\%), "do not want to be recorded" (7\%), "does not feel well" (6\%), "do not want to share personal details" (5\%), and language difficulties (3\%) (Table 4). Thus, 276 patients $(64.6 \%)$ agreed to participate in the EXACKTE2 study, and 265 (96\% of participating patients) completed the questionnaire 2 weeks after the encounter. The 11 patients lost to follow-up were not contacted 2 weeks after the

Table 1. Participation Rates of Eligible Physicians

\begin{tabular}{llll}
\hline & Quebec & Ontario & TOTAL \\
\hline MDs & $78(77)$ & $39(57)$ & $117(69)$ \\
Residents & $91(67)$ & $68(88)$ & $159(75)$ \\
\hline
\end{tabular}

Data are number (\%). encounter. Among those lost to follow-up, 1 was not reachable because the line was out of service, 1 refused to complete the last questionnaire, and 9 were not reached after at least 7 phone calls to each.

The overall mean age of participating patients was 50.7 years, and $69 \%$ were women (Tables 5 and 6). The average age of those refusing to participate was 49.6 years, and $73 \%$ were women.

Given that this study was held in a family practice context, there were multiple reasons for consultation. The patients themselves provided this information after the encounter with the physician. By the end of their contribution, each patient had dedicated about 40 minutes to the project.

Figure 3. Flow diagram of dyad recruitment. FPTU, Family Practice Teaching Units.

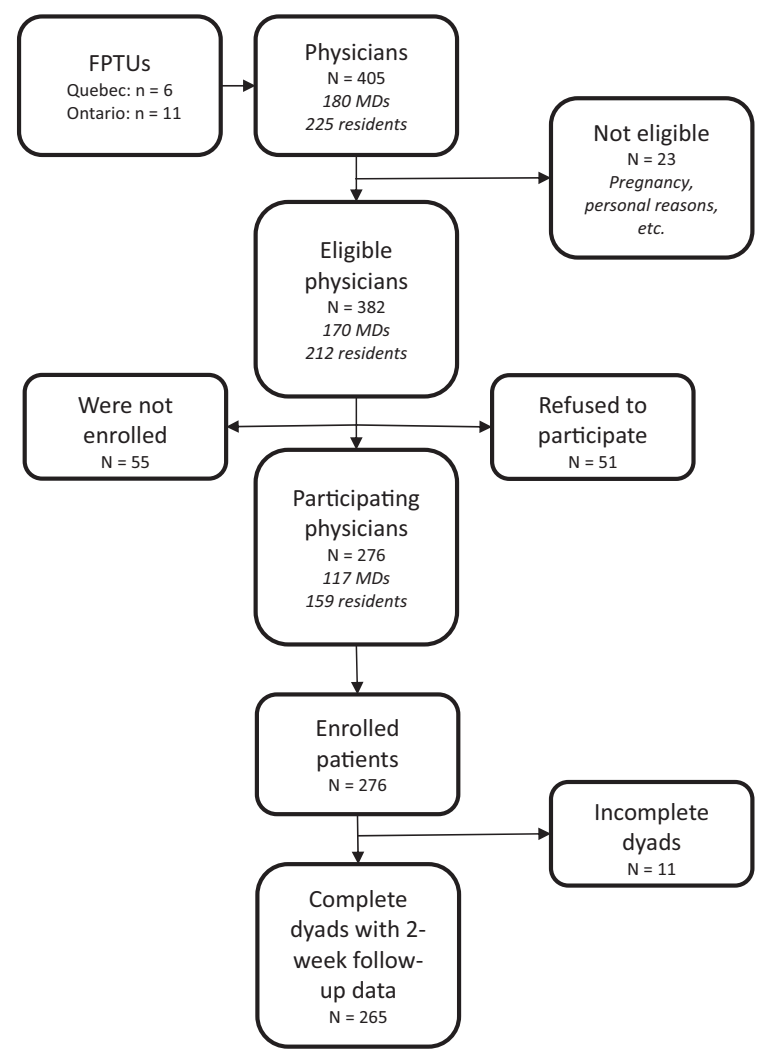


Table 2. Characteristics (Average Age and Sex) of Participating Physicians

\begin{tabular}{lccc}
\hline $\begin{array}{l}\text { MD and Resident } \\
\text { Characteristics }\end{array}$ & Quebec & Ontario & Total \\
\hline Mean age \pm SD & $35.2 \pm 10.6$ & $37.6 \pm 9.6$ & $35.4 \pm 10.9$ \\
Sex (n) & & & \\
Male & 49 & 50 & 99 \\
Female & 120 & 57 & 177 \\
\hline
\end{tabular}

SD, standard deviation.

\section{Costs Linked to Dyad Recruitment}

Throughout the recruitment periods, each RA in Quebec spent a mean of 5.6 hours/week in the practices and each RA in Ontario spent 10.8 hours/ week. Total staff time devoted to dyad recruitment was 1434 hours (5.2 hours/dyad), and total cost in RA salaries was $\$ 34,362$. This translates into an average of CAN\$124.50 per dyad, including time for meeting with the practices, recruiting and obtaining consent of participants, traveling to the sites, and following up with recruited participants. Participants did not receive incentive fees.

\section{Discussion}

Few researchers have accorded sufficient importance to the physician-patient dyadic relationship ${ }^{39}$ and, to the best of our knowledge, none have designed a process to address its specific research challenges. Patient recruitment by physicians is a common method but has several well-known drawbacks. In dyadic research, patient recruitment presents additional challenges. We therefore developed and implemented a systematic dyad recruitment procedure in the context of a cross-sectional study (EXACKTE2). The recruitment reached all the objectives planned. The EXACKTE2 study was successful in recruiting simultaneously a large number of physicians and their patients in 2 PBRNs. While other primary care studies show a physician participation rate close to $50 \%, 8,10,30$ with success varying from one study to another, the average response rate for our study was 69\% (it varied from $57 \%$ to $94 \%$ ). The discussion of the success of our recruitment process is structured around the following 5 important points:

\section{Practice Recruitment}

The large number of practices recruited for this study (17 in total) meant a large number of eligible physicians and access to a large number of patients. It also increased the likelihood of heterogeneity and thus the external validity of the study (some study designs require a minimum number of practices to ensure valid statistical data). In addition, as shown by Dean et $\mathrm{al}^{8}$ in a cross-national European study, the recruitment of participants (physicians and patients) in multiple general practices resulted in higher response rates when whole practices were recruited rather than individual general practitioners within a practice. The agreement of the group as a whole is helpful in obtaining collaboration from individual staff. For all these reasons, the enrollment of practices per se must be considered a critical step in preparing clinical trials in primary care. We successfully used this large-scale recruitment strategy in another large randomized control trial, DECISION + 2, conducted in 12 FPTUs. ${ }^{40,41}$

\section{Physician Recruitment}

Given that primary care physicians' schedules are always very tight - they usually cite lack of time as the main reason for not participating in studies ${ }^{12-14}$ recruiting a sufficient number of physicians is a challenge. In addition, because we were developing a new research model, the questionnaires were voluminous. Physicians contributed about 30 minutes of their time to our study, not including the encounter. The time allocated for recruitment varied from one clinic to another, depending on the number of recruitable physicians in the FPTU and their availability. Goodyear-Smith has pointed out that we should not underestimate the time it takes for recruitment, which may require extensive flexibility on the part of the research team. ${ }^{42}$ In our process this requirement was met by assigning to each practice a part-time RA with a flexible schedule.

Table 3. Participation Rate Among Patients

\begin{tabular}{lrrr}
\hline & Quebec & Ontario & Total \\
\hline Patients solicited (n) & 247 & 183 & 430 \\
Ineligible patients (n) & 4 & 5 & 9 \\
Refusals (n) & 74 & 68 & 142 \\
Withdrawals (n) & 1 & 2 & 3 \\
Participating patients (n) & 167 & 109 & 276 \\
$\begin{array}{l}\text { Patients who completed data } \\
\quad \text { collection at 2-week }\end{array}$ & 159 & 106 & 265 \\
$\quad$ follow-up (n) & & & \\
$\begin{array}{l}\text { Patient recruitment rates } \\
\quad \% \text { ) }\end{array}$ & 67.6 & 59.6 & 64.6 \\
\hline
\end{tabular}


Table 4. Patients' Reasons for Refusing to Participate

\begin{tabular}{lcccc}
\hline Reasons for Refusal to Participate & Quebec & Ontario & Total & Patients (\%) \\
\hline Time constraints & 38 & 38 & 76 & 51 \\
Not interested & 16 & 14 & 30 & 20 \\
Recording the encounter is an issue & 8 & 3 & 11 & 7 \\
Does not feel comfortable & 4 & 5 & 9 & 6 \\
Encounter too personal & 2 & 2 & 5 & 5 \\
Language & 3 & 7 & 10 & 3 \\
Others & 3 & & 5
\end{tabular}

Our results showed a higher participation rate among residents than among family physicians in the EXACKTE2 study. This could be for several reasons. First, there was a larger number of eligible residents than family physicians in the eligible FPTUs, explained by the fact that residents' rounds in FPTUs are of 12 months' duration (July to June), giving access to a new cohort of residents midstudy. Second, while physicians in PBRNs are frequently asked to participate in studies, residents have had less experience with solicitation. Third, residents in family medicine are exposed and sensitized to the importance of primary care research through their training and because of the recent establishment of PBRNs. Last, although we made clear that participating in the study was entirely voluntary and we respected all steps required for informed consent of physicians, including residents, in the study, we cannot exclude that some residents felt compelled to participate for fear of displeasing their clinical teachers, especially if those teachers had enrolled. This is particularly interesting because more than 10 years earlier, the senior investigator (FL) was advised by an hospital-based committee that physicians (including residents) entering such studies could not be considered "study subjects" and that the research ethics committee did not need to review consent forms for physicians. Much has changed since then, and any study recruiting physicians needs to include consent forms for physicians and receive ethics committee approval.
Participants in this study were asked to complete consent forms. Ethical approval for the project was obtained from the Research Ethics Board of the Centre de Santé et de Services Sociaux de la Vieille Capitale in Québec City, Canada (final approval November 25, 2008; ethics no. 2008-2009-23) and the Office of Research Ethics of the University of Western Ontario (final approval July 7, 2009; ethics no. $15712 \mathrm{E})$. Physicians and patients were not financially remunerated for their participation.

\section{Patient Enrollment and Retention}

Despite reported difficulties with sample ascertainment and enrollment of patients, some researchers report that the greatest difficulties are with sample retention. For example, a study by Bordeleau et $\mathrm{al}^{43}$ of quality of life among 235 patients with metastatic breast cancer resulted in only 25 patients completing all 4 data points (baseline and 4, 8, and 12 months). Patients and caregivers may offer resistance to standardized questions with Likert scale responses, preferring to tell more of their story. ${ }^{43}$ Investigators must carefully weigh maintaining low burden, caregiver experience, and associated needs at the end of life against the desire to document the patient. Recording this complexity is the only way to provide the multidimensional evidence necessary to improve care for vulnerable populations, yet is an immense research challenge.

Primary care practice involves a high rate of patient visits and diverse medical conditions. Physicians'

Table 5. Average Age of Participating and Refusing Patients

\begin{tabular}{lcc}
\hline Site & Mean Age of Participating Patients (Years) & $\begin{array}{c}\text { Estimated Mean Age of Patients Who Refused to } \\
\text { Participate (Years) }\end{array}$ \\
\hline Quebec & $48.05 \pm 18.4$ & $48.65 \pm 20.6$ \\
Ontario & $55.34 \pm 15.56$ & $50.56 \pm 17.8$ \\
Total & $50.7 \pm 17.8$ & $49.6 \pm 19.3$ \\
\hline
\end{tabular}


Table 6. Sex of Patients Approached and of Participating Patients

\begin{tabular}{lccccc}
\hline & \multicolumn{2}{c}{$\begin{array}{c}\text { Sex of } \\
\text { Participating } \\
\text { Patients }\end{array}$} & & & \multicolumn{2}{c}{$\begin{array}{c}\text { Sex of Patients } \\
\text { Who Refused to } \\
\text { Participate }\end{array}$} \\
\cline { 2 - 3 } \cline { 5 - 6 } Site & Female & Male & & Female & Male \\
\hline Quebec & 126 & 41 & & 62 & 16 \\
Ontario & 65 & 44 & & 50 & 25 \\
Total & 191 & 85 & & 112 & 41 \\
Patients (\%) & 69 & 31 & & 73 & 27 \\
\hline
\end{tabular}

Data are numbers of patients unless otherwise indicated.

schedules are overloaded and they often fall behind, so that patients wait a long time in the waiting room and then are in a hurry to leave. Although most of the participating patients in our study seemed to feel comfortable with a questionnaire taking 25 minutes to complete, $51 \%$ of the patients refusing to participate pleaded lack of time. Overall, however, our patient recruitment was very successful. More than $64 \%$ of the patients approached agreed to participate- $\mathrm{a}$ much higher participation rate than described in previous primary care studies. ${ }^{44}$

Patient retention also was very successful. More than $96 \%$ of recruited patients completed their second questionnaire by phone 2 weeks after the encounters. We suspect that asking ahead for a time convenient for the patient played a role in the positive response rate.

As mentioned in many other studies, ${ }^{45-47}$ our EXACKTE2 study revealed that participating patients want to be more informed about the study, and many were interested in receiving its results. The order of recruitment also had an impact; having already secured the physicians' consent, RAs were able to advise potential participating patients that their doctors had already agreed to participate in the study, which gave patients added confidence about the research project. Asking physicians to identify eligible patients beforehand prevented the solicitation of potentially ineligible patients.

According to other studies, the kind of active recruitment we performed in EXACKTE2 is likely to be more efficient than passive recruitment. ${ }^{48}$ Face-toface contact between the RA and the patient in the recruitment process is a major facilitator in recruiting and retaining patients in many types of trials. ${ }^{44}$ Furthermore, adequately training the RA is an important factor in improving recruitment and, because patient participation can be positively influenced by appeal- ing to altruistic feelings, ${ }^{49-53}$ RAs should be trained to emphasize the benefits and impacts of the study on patient and system outcomes. The value of an informed approach to patient recruitment cannot be underestimated. ${ }^{34,54}$

\section{Lower Burden for Practice Staff}

Considering workload in primary care practices, physicians and practice staff should carry the lowest possible burden throughout the recruitment process. In our study, the use of RAs was the key factor in reducing this burden. All contact with the physicians and the entire patient recruitment process was conducted with consideration and respect by the RAs. Each day of the study, RAs met the physician before each recruitment round, that is, before the consultations began, to confirm that the physician was willing to participate in the study that day. RAs also made sure to avoid causing any delay in the physician's appointment schedule. This mode of operation was greatly appreciated by the physicians and their staff.

\section{Costs Linked to Dyad Recruitment}

The average cost for enrolling and retaining a dyad in the EXACKTE2 study was low (CAN\$124.50/dyad) when compared with other studies reporting estimated costs. Using a variety of strategies used to recruit couples in a context of prostate cancer, Sadler and colleagues ${ }^{55}$ reported that the cost of recruiting and enrolling a couple ranged from $\$ 152$ to $\$ 1,688$, or an average cost of US\$288. Authors of a clinical trial conducted in 1989 estimated the cost of recruiting single, healthy participants aged 25 to 49 years at US\$907 per recruited participant. ${ }^{56}$ Moreover, a study conducted in 1993 that analyzed 5 recruitment strategies reported a cost range of US\$54 to US\$670 per participant, depending on the strategy used (from media ads to neighborhood canvassing). ${ }^{57}$ To our knowledge, this is the first study to report the cost of recruiting provider-patient dyads in the context of primary care encounters.

\section{Conclusion}

The recruitment strategy in this study was developed to address most of the barriers to clinician and patient participation and was shown to be highly efficient. The EXACKTE2 recruitment of dyads was successful and built a rich and relevant dyadic data set that will be helpful in health care research for years to come. To reduce the cost of active recruitment, in- 
vestigators could consider hiring undergraduate or graduate students with good communication skills who should be provided with a systematic and detailed recruitment procedure and well trained by a senior RA (or investigators) experienced in recruiting the targeted participants. Our systematic process for dyadic research in PBRNs should help guide the design of other successful recruitment processes.

The authors thank Louisa Blair for editing the manuscript.

\section{References}

1. Sellors J, Cosby R, Trim K, et al. Recruiting family physicians and patients for a clinical trial: lessons learned. Fam Pract 2002;19:99-104.

2. Affleck P. The challenge of recruitment. Nurse Res 2005;13:78-84.

3. Easterbrook PJ, Matthews DR. Fate of research studies. J R Soc Med 1992;85:71-6.

4. Holden G, Rosenberg G, Barker K, Tuhrim S, Brenner B. The recruitment of research participants: a review. Soc Work Health Care 1993;19:1-44.

5. Sutherland VJ, Cooper CL. Job stress, satisfaction, and mental health among general practitioners before and after introduction of new contract. BMJ 1992;304:1545-8.

6. Bower P, Wilson S, Mathers N. Short report: how often do UK primary care trials face recruitment delays? Fam Pract 2007;24:601-3.

7. Hannay D, Usherwood T, Platts M. Workload of general practitioners before and after the new contract. BMJ 1992;304:615-8.

8. Dean SC, Harper CE, Cappuccio FP, et al. The challenges of cross-national research in primary health care across Europe. Fam Pract 2005;22:341-6.

9. Steinhauser KE, Clipp EC, Hays JC, et al. Identifying, recruiting, and retaining seriously-ill patients and their caregivers in longitudinal research. Palliat Med 2006;20:745-54.

10. Fulda KG, Hahn KA, Young RA, et al. Recruiting practice-based research network (PBRN) physicians to be research participants: lessons learned from the North Texas (NorTex) Needs Assessment Study. J Am Board Fam Med 2011;24:610-5.

11. Ross S, Grant A, Counsell C, Gillespie W, Russell I, Prescott R. Barriers to participation in randomised controlled trials: a systematic review. J Clin Epidemiol 1999;52:1143-56.

12. Taylor KM, Margolese RG, Soskolne CL. Physicians' reasons for not entering eligible patients in a randomized clinical trial of surgery for breast cancer. N Engl J Med 1984;310:1363-7.

13. Taylor KM. The doctor's dilemma: physician participation in randomized clinical trials. Cancer Treat Rep 1985;69:1095-100.
14. Benson AB 3rd, Pregler JP, Bean JA, Rademaker AW, Eshler B, Anderson K. Oncologists' reluctance to accrue patients onto clinical trials: an Illinois Cancer Center study. J Clin Oncol 1991;9:2067-75.

15. Taylor KM, Kelner M. Interpreting physician participation in randomized clinical trials: the Physician Orientation Profile. J Health Soc Behav 1987;28:389-400.

16. Shea S, Bigger JT Jr, Campion J, et al. Enrollment in clinical trials: institutional factors affecting enrollment in the cardiac arrhythmia suppression trial (CAST). Control Clin Trials 1992;13:466-86.

17. Penn ZJ, Steer PJ. Reasons for declining participation in a prospective randomized trial to determine the optimum mode of delivery of the preterm breech. Control Clin Trials 1990;11:226-31.

18. Ward E, King M, Lloyd M, Bower P, Friedli K. Conducting randomized trials in general practice: methodological and practical issues. Br J Gen Pract 1999;49:919-22.

19. Huibers MJ, Bleijenberg G, Beurskens AJ, et al. An alternative trial design to overcome validity and recruitment problems in primary care research. Fam Pract 2004;21:213-8.

20. McDonald AM, Knight RC, Campbell MK, et al. What influences recruitment to randomised controlled trials? A review of trials funded by two UK funding agencies. Trials 2006;7:9.

21. Morse EV, Simon PM, Besch CL, Walker J. Issues of recruitment, retention, and compliance in community-based clinical trials with traditionally underserved populations. Appl Nurs Res 1995;8:8-14.

22. Foley JF, Moertel CG. Improving accrual into cancer clinical trials. J Cancer Educ 1991;6:165-73.

23. Coran JJ, Koropeckyj-Cox T, Arnold CL. Are physicians and patients in agreement? Exploring dyadic concordance. Health Educ Behav 2013;40:603-11.

24. Dobkin PL, De Civita M, Abrahamowicz M, et al. Patient-physician discordance in fibromyalgia. J Rheumatol. 2003;30:1326-34.

25. Legare F, Stewart M, Frosch D, et al. EXACKTE(2): exploiting the clinical consultation as a knowledge transfer and exchange environment: a study protocol. Implement Sci 2009;4:14.

26. Legare F, Turcotte S, Robitaille H, et al. Some but not all dyadic measures in shared decision making research have satisfactory psychometric properties. J Clin Epidemiol 2012;65:1310-20.

27. Kenny DA, Veldhuijzen W, Weijden Tv, et al. Interpersonal perception in the context of doctor-patient relationships: a dyadic analysis of doctor-patient communication. Soc Sci Med. 2010;70:763-8.

28. Miller DK, Chibnall JT. Strategies for recruiting patients into randomized trials of palliative care. Palliat Med 2003;17:556-7.

29. Ewing G, Rogers M, Barclay S, McCabe J, Martin A, Todd C. Recruiting patients into a primary care based study of palliative care: why is it so difficult? Palliat Med 2004;18:452-9. 
30. Williamson MK, Pirkis J, Pfaff JJ, et al. Recruiting and retaining GPs and patients in intervention studies: the DEPS-GP project as a case study. BMC Med Res Methodol 2007;7:42.

31. Wilson K, Roe B. Interviewing older people by telephone following initial contact by postal survey. J Adv Nurs 1998;27:575-81.

32. Jancey J, Howat P, Lee A, et al. Effective recruitment and retention of older adults in physical activity research: PALS study. Am J Health Behav 2006; 30:626-35.

33. Primary health care: Medical Research Council topic review. London: Medical Research Council; 1997.

34. Leathem CS, Cupples ME, Byrne MC, et al. Identifying strategies to maximise recruitment and retention of practices and patients in a multicentre randomised controlled trial of an intervention to optimise secondary prevention for coronary heart disease in primary care. BMC Med Res Methodol 2009;9:40.

35. Johnston S, Liddy C, Hogg W, Donskov M, Russell G, Gyorfi-Dyke E. Barriers and facilitators to recruitment of physicians and practices for primary care health services research at one centre. B Med Res Methodol 2010;10:109.

36. Leblanc A, Legare F, Labrecque M, et al. Feasibility of a randomised trial of a continuing medical education program in shared decision-making on the use of antibiotics for acute respiratory infections in primary care: the DECISION+ pilot trial. Implement Sci 2011;6:5.

37. Legare F, Labrecque M, LeBlanc A, et al. Training family physicians in shared decision making for the use of antibiotics for acute respiratory infections: a pilot clustered randomized controlled trial. Health Expect 2011;14(Suppl 1):96-110.

38. Gagnon S, Labrecque $M$, Njoya M, Rousseau F, St-Jacques S, Legare F. How much do family physicians involve pregnant women in decisions about prenatal screening for Down syndrome? Prenat Diagn 2010;30:115-21.

39. Murphy E, Kinmonth AL, Marteau T. General practice based diabetes surveillance: the views of patients. Br J Gen Pract 1992;42:279-83.

40. Legare F, Labrecque M, Godin G, et al. Training family physicians and residents in family medicine in shared decision making to improve clinical decisions regarding the use of antibiotics for acute respiratory infections: protocol for a clustered randomized controlled trial. BMC Fam Pract 2011;12:3.

41. Légaré F, Labrecque M, Cauchon M, Castel J, Turcotte S, Grimshaw J. Training family physicians in shared decision-making to reduce the overuse of antibiotics in acute respiratory infections: a cluster randomized trial. CMAJ 2012;184:E726-34.

42. Goodyear-Smith F, York D, Petousis-Harris H, et al. Recruitment of practices in primary care research: the long and short of it. Fam Pract 2009;26:128-36.
43. Bordeleau L, Szalai JP, Ennis M, et al. Quality of life in a randomized trial of group psychosocial support in metastatic breast cancer: overall effects of the intervention and an exploration of missing data. J Clin Oncol 2003;21:1944-51.

44. Bakken S, Lantigua RA, Busacca LV, Bigger JT. Barriers, enablers, and incentives for research participation: a report from the Ambulatory Care Research Network (ACRN). J Am Board Fam Med 2009;22:436-45.

45. Morrison W. Trials and tribulations: patients' perspectives of the Betaseron study. Axone 1994;16:51-5.

46. Corbett F, Oldham J, Lilford R. Offering patients entry in clinical trials: preliminary study of the views of prospective participants. J Med Ethics 1996;22:227-31.

47. Maslin A. A survey of the opinions on 'informed consent' of women currently involved in clinical trials within a breast unit. Eur J Cancer Care (Engl) 1994;3:153-62.

48. Raynor HA, Osterholt KM, Hart CN, Jelalian E, Vivier P, Wing RR. Evaluation of active and passive recruitment methods used in randomized controlled trials targeting pediatric obesity. Int J Pediatr Obes 2009; 4:224-32.

49. Cassileth BR, Lusk EJ, Miller DS, Hurwitz S. Attitudes toward clinical trials among patients and the public. JAMA 1982;248:968-70.

50. Burgess LJ, Sulzer NU, Hoosain F, Leverton N, Bliganut S, Emanuel S. Patients' motivations for participating in cardiovascular clinical trials: a local perspective. Cardiovasc J Afr 2009;20:220-3.

51. Jenkins V, Fallowfield L. Reasons for accepting or declining to participate in randomized clinical trials for cancer therapy. Br J Cancer 2000;82:1783-8.

52. Verheggen FW, Nieman F, Jonkers R. Determinants of patient participation in clinical studies requiring informed consent: why patients enter a clinical trial. Patient Educ Couns 1998;35:111-25.

53. Hollada J, Marfori W, Tognolini A, Speier W, Ristow L, Ruehm SG. Successful patient recruitment in CT imaging clinical trials: what factors influence patient participation? Acad Radiol 2014;21:52-7.

54. Dolan G, Broomfield J, Lewith G, Watkins A. Operational and resource management of an RCT: some of the pitfalls and lessons learned. J Clin Nurs 1999;8: 389-95.

55. Sadler GR, Ko CM, Malcarne VL, Banthia R, Gutierrez I, Varni JW. Costs of recruiting couples to a clinical trial. Contemp Clin Trials 2007;28:423-36.

56. Borhani N, Tonascia J, Schlundt D, Prineas R, Jeffreys J. Recruitment in the Hypertension Prevention Trial. Hypertension Prevention Trial Research Group. Control Clin Trials 1989;10(3 Suppl):30S-9S.

57. Bjornson-Benson W, Stibolt T, Manske K, Zavela $\mathrm{K}$, Youtsey D, Buist AS. Monitoring recruitment effectiveness and cost in a clinical trial. Control Clin Trials 1993;14(2 Suppl):52S-67S. 